\title{
Thoracic surgery in Taiwan
}

\section{Xing Gao, Yin-Kai Chao^}

Division of Thoracic Surgery, Chang Gung Memorial Hospital-Linkou, Chang Gung University, Taoyuan

Contributions: (I) Conception and design: Both authors; (II) Administrative support: Both authors; (III) Provision of study materials or patients: Both authors; (IV) Collection and assembly of data: Both authors; (V) Data analysis and interpretation: Both authors; (VI) Manuscript writing: Both authors; (VII) Final approval of manuscript: Both authors.

Correspondence to: Prof. Yin-Kai Chao, MD, PhD. Division of Thoracic Surgery, Chang Gung Memorial Hospital- Linkou, No5. Fu-Hsing Street, Taoyuan. Email: chaoyk@cgmh.org.tw.

\begin{abstract}
Taiwanese surgeons have pioneered major advances in the field of minimally invasive thoracic surgery. Since the establishment of the Taiwan Association of Thoracic and Cardiovascular Surgery [1986], the landscape of thoracic surgery has rapidly evolved from traditional thoracotomy to multi-port videoassisted thoracoscopic approaches. By early 21 st century, further developments have included the singleport and subxiphoid techniques. This paper provides an overview of the Taiwanese thoracic surgery environment and its major accomplishments. With the increasing use of low-dose computed tomography for lung cancer screening, the detection of small pulmonary nodules has been growing steadily. High-end hybrid operating rooms comprising both imaging and surgical equipment are increasingly being applied in Taiwan as platforms for image-guided video-assisted thoracoscopic surgery (iVATS). Recently, we described an iVATS workflow for simultaneous detection and removal of small pulmonary nodules which was entirely performed by thoracic surgeons. With respect to esophageal malignancies, the implementation of robotassisted esophagectomy has been a significant milestone in Taiwan. This technique allowed conducting an extensive lymph node dissection along the bilateral recurrent laryngeal nerve in a safe and effective manner. With 14 medical schools and 26 medical centers located on the island, Taiwan has been able to maintain a constant doctor-to-population ratio of 1-to-500. By partnering with the National Health Insurance and by taking advantage of state-of-the-art technologies, Taiwanese thoracic surgeons are continuously striving to deliver high-quality and cost-effective surgical care.
\end{abstract}

Keywords: Thoracic surgery; Taiwan; video-assisted thoracoscopic surgery (VATS); hybrid operating room; robot-assisted minimally invasive esophagectomy (RAMIE)

Submitted Aug 09, 2021. Accepted for publication Dec 02, 2021.

doi: $10.21037 /$ jtd-21-1302

View this article at: https://dx.doi.org/10.21037/jtd-21-1302

\section{The healthcare system and the development of thoracic surgery in Taiwan}

Taiwan is an island located north of South China Sea, about $180 \mathrm{~km}$ off the southeastern coast of China, with a total area of $36,000 \mathrm{~km}^{2}$ and a population of approximately 23 million people. While at the beginning of the twentieth century the Taiwanese medical system was largely influenced by the Japanese healthcare model, over the last decades it has been largely shaped by organization schemes derived from Western countries. Along with innovation and economic growth, Taiwan has always been committed to deliver high quality health and public health services (1). At present, the Taiwanese medical teaching system consists of three public, one military, and nine private medical schools from which at least 1,300 students graduate annually (Figure 1). Although the stable physician supply has been able to maintain a

\footnotetext{
$\wedge$ ORCID: 0000-0001-8649-8783.
} 


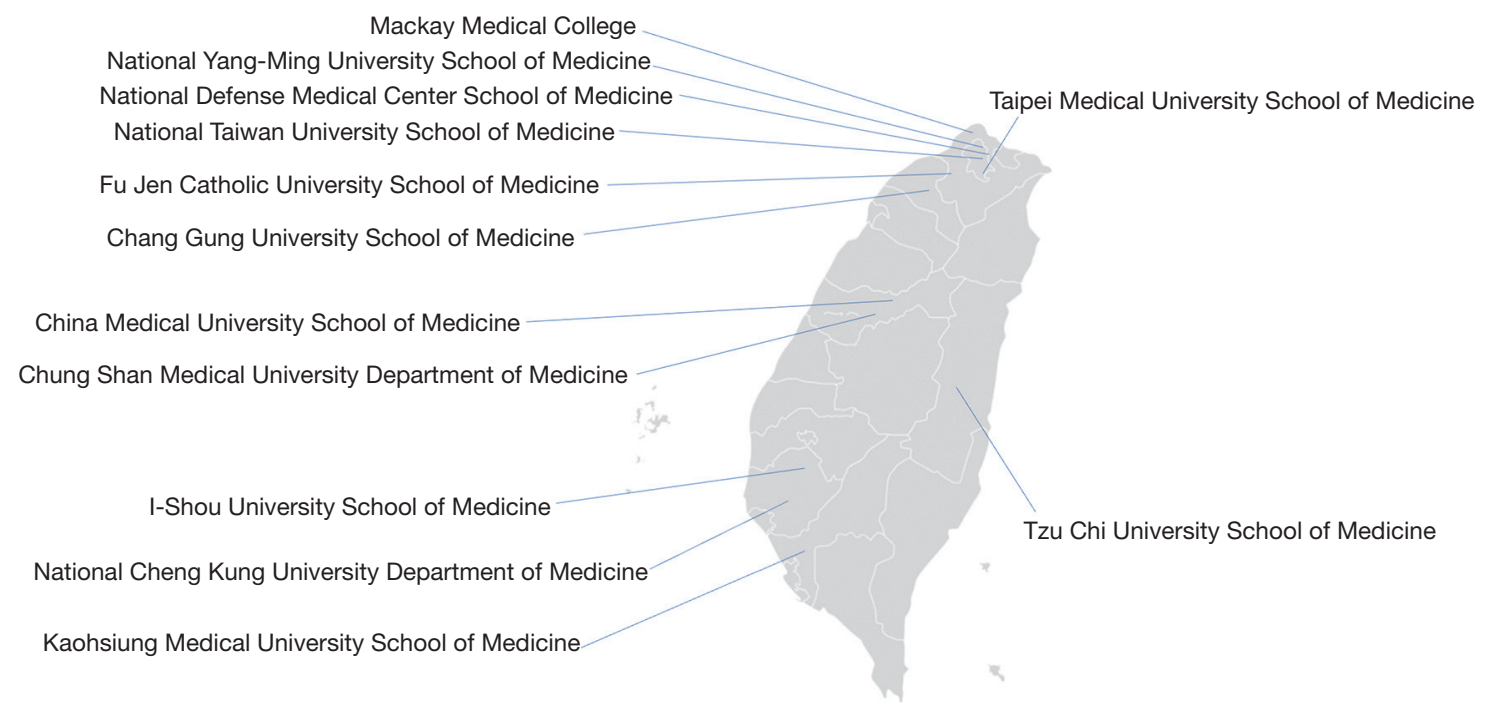

Figure 1 Geographic distribution of Taiwanese medical schools.

constant doctor-to-population ratio of 1:500, medical resources are unequally distributed throughout the 20 Taiwanese counties. While the doctor-to-population ratio is as high as 1-to-260 in Taipei city, this decreases to 1-to1,600 in rural areas (2).

A key milestone on the path to population health in Taiwan was the establishment of the National Health Insurance (NHI) in 1995. Before the introduction of the NHI, there were significant fragmentations in the available health insurance schemes and only half of the population had adequate coverage-resulting in inequitable benefit packages. The implementation of the NHI system consolidated the pre-existing tiered health insurance model and created a single-payer national health insurance scheme. As a result, $99.9 \%$ of the Taiwanese population was entitled to receive full reimbursement of healthcare expenditures by the end of $2004(3,4)$. After the NHI has been established, improved physical and mental health at the population level accounted for a significant increase in the Taiwanese gross domestic product (GDP)—which surpassed the world's average-while maintaining a relatively low health spending-to-GDP ratio (6.1\% in Taiwan vs. $16.9 \%$ in the United States, and $10.9 \%$ in Japan). Life expectancy in Taiwan currently ranks 26th in the world-being 77.7 years for men and 84.2 years for women (5).

Recent years have witnessed significant efforts in enhancing knowledge transfer between the 26 medical centers located on the island, and this has been particularly relevant in the field of thoracic surgery. While the history of this discipline in Taiwan dates back to the late 1950s, it was not until 1986 when the Taiwan Association of Thoracic and Cardiovascular Surgery (TATCS, http://www.tatcs.org. tw/) has been officially established (Figure $2 A$ ). Following completion of their basic medical degrees, all aspiring Taiwanese thoracic surgeons should attend a postgraduate training over 6 or 7 years, including 2 years of general training, 2 or 3 years of general surgery training (depending on previous track records), and 2 years of thoracic training. Recently, rapid technical and technological innovation has transformed thoracic surgery into one of the most rapidly developing surgical specialties on the island. As a result, a novel scientific society-termed Taiwan Society of Thoracic Surgeons (TSTS, http://www.tsts.org.tw/)—has been created in 2018 to foster networking and promote progress within this specific field (Figure 2B).

\section{Thoracic diseases}

\section{Lung cancer (LC)}

Despite decades of research for what remains a major public health problem, LC is still the leading cause of cancerrelated mortality in Taiwan. In 2014, a total of 12,462 new LC cases have been documented, representing $12.1 \%$ of all cancer diagnoses in the area. Additionally, 9,167 people died of LC during that year, accounting for $19.9 \%$ of all cancer-related deaths. In general, the most common histological subtype is non-small cell LC-which represents $85 \%$ of all cases. Only $25 \%$ of all patients are eligible for 

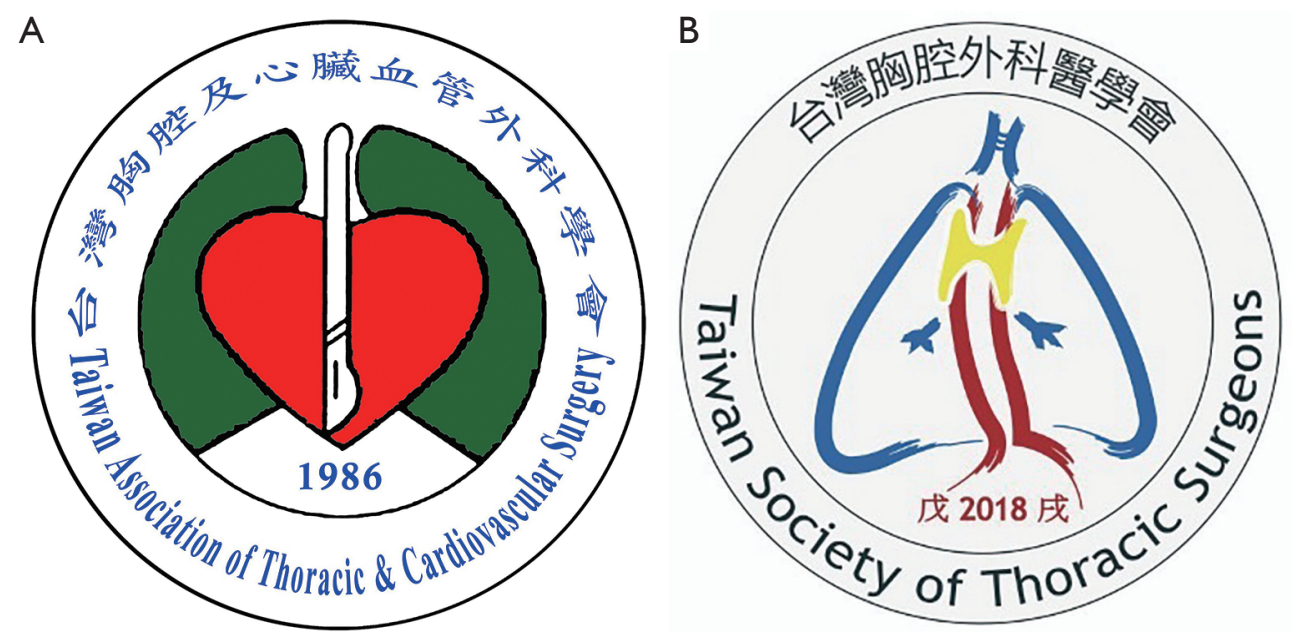

Figure 2 Associations related to thoracic surgery in Taiwan. (A) Official logo of the Taiwan Association of Thoracic and Cardiovascular Surgery; (B) Official logo of Taiwan Society of Thoracic Surgeons.

treatment with curative intent and clinical outcomes remain unfavorable [5-year overall survival (OS) rate: $<15 \%](6)$. The use of low-dose computed tomography (LDCT) for LC screening has become increasingly popular in recent years, and the number of asymptomatic patients referred to thoracic surgeons because of suspected LC in need of surgical excision has been growing steadily (7). Recently, a screening trial (TALENT study) has been implemented in Taiwan and eligibility to undergo LDTC has been noticeably extended to non-smokers who harbor other risk factors (e.g., family history of LC or a high cooking index) (8). Of the 12,011 study participants, $2.6 \%$ were found to have LCa prevalence that surpassed those reported in the NELSON and NLST studies $(0.9 \%$ and $1.1 \%$, respectively) $(7,9)$. Application of LDTC screening programs and the resulting increased detection of small pulmonary nodules have prompted the implementation of less invasive techniques in the field of lung surgery. Additionally, the annual LC surgery volume has increased from 2,957 in 2010 to 9,668 in 2020; in parallel, the percentage of sublobar resections has been growing from $37 \%$ to $66.5 \%$. As of 2007 , all thoracoscopic lung resections-including wedge resection, lobectomy, and pneumonectomy-are fully reimbursed by the NHI. Complete cost coverage for pulmonary segmentectomy has been introduced in 2014 .

\section{Esophageal cancer (EC)}

Estimates derived from epidemiological data have shown that $>80 \%$ of all patients diagnosed with EC are living in Asia (10).
The high prevalence of risky lifestyles for EC in Asian countries - including the use of hot drinks, foods containing $\mathrm{N}$-nitroso compounds, alcohol consumption, and tobacco smoking-is recognized to have a major impact in shaping the peculiar geographical distribution of this malignancy (11-15). In 2015, EC was the ninth most common cause of cancer-related mortality in Taiwan (mortality rate: 5.1 deaths per 100,000 people); unfortunately, the survival figures continue to remain unfavorable (5-year OS rate: $16.8 \%$; median survival time: 343 days). Taiwanese patients with EC are generally diagnosed at advanced stages (clinical stage I, II, III, and IV: $7.8 \%, 16.6 \%, 46.1 \%$, and $25.4 \%$, respectively), and the most common histological type is squamous cell carcinoma.(16) Treatment approaches may vary from endoscopic mucosal resection to esophagectomy, chemotherapy, radiotherapy, and, more recently, immunotherapy. Approximately $35 \%$ of Taiwanese patients diagnosed with EC are eligible for esophagectomy, either with or without preoperative chemoradiotherapy (17). As of 2008, the costs of minimally invasive esophagectomy (MIE) are entirely covered by the NHI. Recent years have witnessed an increase in surgical volumes for both traditionally esophagectomy and MIE. On analyzing the cost-effectiveness of MIE $v s$. open esophagectomy in a population-based study, we have recently found that the less invasive approach represents a viable cost-effective option in Taiwan (18).

\section{Other diseases of the thorax}

While most operations fall within the field of oncology 
(i.e., removal of pulmonary or esophageal malignancies), Taiwanese thoracic surgeons also treat patients with benign disorders (e.g., pneumothorax, chest wall malformations, benign mediastinal masses, myasthenia gravis) and are involved in transplantation procedures. Over the last several years, one of the major focuses has been the treatment of primary spontaneous pneumothorax - which is characterized by high recurrence rates. In 2013, Chen and coworkers (19) demonstrated that additional minocycline pleurodesis after standard treatment (i.e., simple aspiration and drainage) significantly reduced the rates of recurrence (from $49 \%$ to $29 \%$; $\mathrm{P}=0.003$ ). Since then, this approach has become the standard of care. Recent advances in minimally invasive surgery have led to the application of thoracoscopic stapled bullectomy along with the use of a vicryl mesh to cover the staple line. This technique has further reduced the recurrence rate to $2.9 \%$ (20). Collectively, these results indicate that minimally invasive surgical approaches produced significantly better outcomes for both benign and malignant thoracic diseases.

\section{Techniques in thoracic surgery}

\section{Video-assisted thoracoscopic surgery (VATS)}

Taiwanese thoracic surgeons have pioneered major advances in the field of VATS. The first VATS procedure performed in Taiwan dates back to early 1993 and was carried out by Liu and coworkers; this seminal operation paved the way to a number of subsequent refinements and improvementsincluding the application of this technique for anatomical lung resection, mediastinal tumor excision, and esophagectomy $(21,22)$. Interestingly, a population-based cost analysis has shown that thoracoscopic lobectomy outperforms open lobectomy by reducing both length of stay and surgical mortality ( $0.41 \%$ vs. $1.04 \%$, respectively, $\mathrm{P}=0.0096)$ ultimately favoring the VATS approach (23). On analyzing esophagectomy for cancer, we have previously shown that the use of VATS in Taiwan increased from 30\% in 2008 to $88 \%$ in 2015, and this in turn resulted in a significant decrease of 90-day postoperative mortality (from $7.7 \%$ to $5.8 \%$ ) (18).

A major milestone in moving VATS towards a less invasive approach was established by Rocco and colleagues (24), who described for the first time the single-port technique for pulmonary wedge resection. In Taiwan, Wang et al. (25) not only implemented the use of single-port lobectomy and segmentectomy as of 2010 but also demonstrated that the single-port approach was not inferior to the traditional multi-port VATS technique as far as major lung resections are concerned. These findings were subsequently confirmed and expanded in a multicenter study by Hsu et al. (26). As for esophagectomy, Liu and colleagues published in 1995 the first case series of patients who underwent thoracoscopic esophageal mobilization and intrathoracic anastomosis using a minimally invasive approach (27). However, MIE remained underutilized until 2008, when the NHI started to offer complete cost coverage. In 2016, Lee et al. (28) described a significant technical refinement by which MIE was carried out using a single incision for both the thoracoscopic and laparoscopic procedures. The same authors subsequently undertook a propensity score-matched analysis to compare the postoperative outcomes of single$v s$. multiple-incision MIE. They found that postoperative pain in the first post-surgical week was significantly reduced in patients who had undergone single-incision MIE (29). A randomized clinical trial (NCT03646110) is currently being performed to analyze the oncological outcomes of the two approaches. Another study compared single-port $v s$. conventional VATS for the removal of mediastinal tumors (30). The results revealed that patients treated with single-port VATS showed lower postoperative pain and a shorter postoperative length of stay compared with those who received the standard procedure.

A subsequent development in the field of single-port VATS was the adoption of the subxiphoid approach. Although the use of VATS dramatically reduced the amount of surgical trauma, the unavoidable compression of the intercostal nerves may account for the lack of differences in chronic postoperative pain between patients treated with the endoscopic approach $v s$. open thoracotomy (31). The use of the subxiphoid technique allows avoiding intercostal incisions, ultimately reducing the risk of injuries to the intercostal nerves and postoperative neural pain. The subxiphoid approach has been traditionally applied in the field of mediastinal surgery. In Taiwan, Hsu and coworkers pioneered the use of the subxiphoid approach for performing thymectomy and extended thymothymectomy in patients with myasthenia gravis as of $2002(32,33)$. After more than a decade, Liu et al. (34) applied for the first time the subxiphoid technique for conducting pulmonary lobectomy. It is likely that this approach would result in reduced postoperative pain, but additional research is necessary to examine this hypothesis more rigorously.

Thoracoscopic surgery in general and single-port VATS in particular have been well-received by Taiwanese thoracic surgeons and both approaches are increasingly being 
applied in surgical oncology as well as for the treatment of benign thoracic disorders or chest wall deformities (35). Further clarification of the actual benefits conferred by repetitively minimizing surgical accesses and a thorough analysis of long-term oncological outcomes will likely assist in our understanding of how best to harness the clinical potential of minimally invasive approaches.

\section{Image-guided video-assisted thoracoscopic surgery (iVATS)}

As previously mentioned, a large number of small pulmonary nodules and early-stage LC are currently being identified through lung cancer screening programs. Unfortunately, VATS has limitations for removal of both ground glass opacities (GGOs) and nodules of less than $1 \mathrm{~cm}$ in size. Accordingly, these lesions are frequently thoracoscopically invisible and impalpable (36). In this scenario, precise preoperative lesion localization is a key prerequisite to their successful removal. Traditionally, small pulmonary nodules are excised through a two-step approach-with lesion localization in a CT suite as the first step followed by lesion removal in an operating room as the second step. The advent of hybrid operating rooms (HORs) has fostered our ability to offer a more patienttailored approach that allows simultaneous localization and removal of small pulmonary nodules within a single session. Specifically, HORs-which are complex infrastructures with high-end imaging and surgical equipment-can be utilized as platforms for iVATS. The first report on tumor localization in the HOR dates back to 2015 and several studies have subsequently confirmed the clinical usefulness of this approach (37). Lesion localization within the HOR has been traditionally accomplished by radiologists. However, our surgical team has pioneered a novel iVATS workflow that for the first time was entirely performed by thoracic surgeons (38). The procedure was characterized by a significant learning curve as demonstrated by decreased localization time and radiation exposure occurring with increased surgical experience (39). Importantly, the technique is performed with the patient lying in the lateral decubitus position for lesion localization. Avoidance of the supine or prone positions allows accomplishing localization and surgery without patient repositioning. In addition, our retrospective comparison study demonstrated that thoracic surgeons can coordinate and carry out the localization procedure as effectively as interventional radiologists (40). More importantly, the time interval from localization to surgery was significantly reduced by the use of a HOR. A prospective randomized study (NCT03395964) is currently being performed to further increase the evidence in support of the iVATS procedure (41).

\section{Tubeless VATS}

Tubeless VATS - another form of minimally invasive thoracic surgery-was initially developed in the field of anesthesiology to minimize the adverse effects of general anesthesia, including neuromuscular blockade and intubation-related complications (e.g., airway trauma). The possibility of conducting awake thoracic surgery was considered unrealistic until Pompeo and coworkers (42) demonstrated the feasibility of this approach in 2004. In Taiwan, the group of Chen and colleagues $(43,44)$ has fostered the application of this technique to major pulmonary resections-including segmentectomy and lobectomy - and mediastinal lymph node dissection. Using a combination of sedative drugs and intrathoracic vagal blockade, they were able to accomplish these surgical goals with the same proficiency as in intubated patients under general anesthesia. The benefits inherent to this approachincluding shorter hospital stays, lower procedural costs, and a reduced complication burden-have prompted additional investigations of this technique (45).

Another notable advantage offered by tubeless VATS is the possibility to implement a no-drain policy. In this regard, a randomized trial that compared the efficacy and safety of VATS with and without drainage tube placement after pulmonary wedge resection showed that the drainless approach resulted in shorter hospital stays, lower procedural costs, and reduced postoperative pain (46).

\section{Robotic thoracic surgery}

The first installation of a robotic surgical system in Taiwan dates back to 2004 and it is estimated that over 40 surgical robots are currently available in Taiwan. The main technical advantages offered by robotic surgery-including threedimensional vision, wristed instrumentation, tremor filtering, and an improved (10x) magnification-allow performing precise movements in limited surgical spaces. This makes this approach particularly advantageous when delicate dissections and suturing in the deep anatomical spaces are required. However, no robotic procedures other than radical prostatectomy and partial nephrectomy are entitled to public health coverage in Taiwan, and mixed billing is not permitted. This policy has resulted in significant barriers 
to the implementation of other robot-assisted procedures, including those in the field of thoracic surgery. Historically, the initial applications of thoracic robotic surgery in Taiwan were in the field of MIE. In this scenario, robot-assisted minimally invasive esophagectomy (RAMIE) holds promise to overcome the technical limitations of traditional MIE, especially in the field of upper mediastinum lymph node dissection. While in Western countries most esophageal adenocarcinomas affect the lower third of the esophagus, the majority of Asian patients with esophageal malignancies have esophageal squamous cell carcinomas (ESCC) located in the upper or middle thirds. Metastases to upper mediastinal nodes are commonly seen in Taiwanese patients with ESCC. While an extensive lymph node dissection along the bilateral recurrent laryngeal nerve (RLN) is paramount to improve outcomes in this patient group, the procedure has been traditionally limited by a high post-procedural morbidity. In 2017, we demonstrated for the first time the clinical utility of extensive nodal dissection along the RLN performed during the course of RAMIE (47). In another study, we showed that the application of this robotic technique was characterized by a significant learning curve; following the acquisition of a certain proficiency threshold, a significant reduction of post-procedural RLN palsy was observed (48). A multicenter randomized trial—termed REVATE (NCT03713749)— is currently ongoing with the aim of comparing the rates of successful RLN nodal dissection during RAMIE vs. MIE. The initial study findings are expected for summer 2022 (49).

Apart from RAMIE, other robotic thoracic proceduresincluding the use of a trans-subxiphoid access for anterior mediastinal diseases and transthoracic sympathetic trunk reconstruction (STR) after previous endoscopic transthoracic sympathectomy (ETS) - have been recently described by our group $(50,51)$. ETS represents a viable therapeutic option for patients with primary regional hyperhidrosis who are refractory to standard medical treatment. Taiwan has been among the first regions to implement this procedure in the late 1980s, and it is currently estimated that approximately one quarter of all Taiwanese patients suffering from primary palmar hyperhidrosis had been treated with ETS (52). Unfortunately, some cases may ultimately develop severe and intolerable post-ETS compensatory sweatingwhich can be reversed through the application of robotic STR. Our group performs this operation through a multidisciplinary approach that involves two distinct teams specializing in thoracic surgery and plastic-reconstructive surgery (microsurgery subspecialty), respectively. Such a combination may allow achieving an increased attention to fine surgical details, which eventually results in sustained clinical benefits (53).

\section{Lung transplantation}

Taiwan has a long-standing tradition in the field of lung transplantation as attested by the fact that the two first single- and double-lung transplantation procedures conducted in Asia were carried out in Taiwan (Wang, 1991 and Lee, 1994, respectively). Despite this pioneering role, the Taiwanese lung transplant community continues to be faced by an undeniable organ shortage. Potential candidates for lung transplantation include patients with chronic obstructive pulmonary disease, pulmonary arterial hypertension, cystic fibrosis, idiopathic pulmonary fibrosis, lymphangioleiomatosis, pneumoconiosis, and other chronic lung diseases (54). The Taiwan Organ Registry and Sharing Center (TORSC) is in charge of patient allocation in the transplant waiting list, whereas lung procurement is performed according to the criteria set forth by the International Society for Heart and Lung Transplantation. In 2017, Yang and coworkers (55)-the largest group dedicated to lung transplantation in Taiwanpublished the results of their cumulative experience that spanned over a 20 -year period. While the results obtained during the first decade remained suboptimal, a significant improvement was observed over the last 10 years. However, according to an official nationwide TORSC report issued in 2018, the survival rates of Taiwanese patients who had undergone lung transplantation between April 2006 and December 2018 were $71.03 \%, 54.81 \%$, and $42.46 \%$ at 1 , 3 , and 5 post-transplantation years, respectively. These figures are markedly less favorable than the average survival rates published by the International Society for Heart and Lung Transplantation. The potential reasons underlying the seemingly survival disadvantage observed in Taiwan have not been thoroughly examined. The reduced procedural volume-which has remained limited for several years-may offer a potential explanation. While none of the ten certified lung transplant centers in Taiwan has been able to perform more than 10 lung transplantations per year until 2018, the landscape is slowly improving. As of 2019, two medical centers-the National Taiwan University Hospital and the Chang Gung Memorial Hospital-Linkou-have acted as centralized institutes and have been able to conduct more than 20 lung transplants per year. Unfortunately, organ shortage still poses a limitation regarding the ability of these 
centers to reach a "high-volume" status. Despite this caveat, the increasing number of procedures has been paralleled by promising improvements in terms of short-term survival.

\section{Conclusions}

Recent years have witnessed rapid technical advances in the field of thoracic surgery. For example, we not only moved from traditional thoracotomy to a multi-port thoracoscopic approach, but we went a step ahead with the implementation of the single-port technique and the application of the subxiphoid approach. Currently, several minimally invasive techniques_-including tubeless VATS—hold promise for minimizing surgical trauma and are currently being applied by a growing number of Taiwanese surgeons. In the field of small pulmonary nodules, Taiwan has pioneered a proactive involvement of thoracic surgeons for simultaneous lesion localization and removal during iVATS performed in highend HORs. One needs to be aware that novel surgical approaches do not come without challenges-especially with respect to cost-effectiveness compared with traditional techniques. However, it can equally be argued that a concerted and coordinated nationwide effort in research, education, and advocacy-along with the ongoing technical refinements-is precisely what is required at this juncture to reboot and turbocharge the landscape of Taiwanese thoracic surgery.

Now this is not the end. It is not even the beginning of the end. But it is, perhaps, the end of the beginning. - Winston Churchill.

\section{Acknowledgments}

The authors want to acknowledge the following leaders and their staff for providing data and sharing their thoughts on the landscape of thoracic surgery in Taiwan: Professor Jan-Ming Lee (Honorary President of TATCS), Professor Tsai-Wang Huang (Deputy Secretary General of TATCS), Professor Chung-Ping Hsu (Honorary President of TATS), Professor Han-Shui Hsu (President of TATS), and Professor Jin-Shing Chen (Secretary General of TATS).

Funding: This study was financially supported by a grant (No. CMRPG3K0762) from the Chang Gung Memorial Hospital (Taiwan).

\section{Footnote}

Provenance and Peer Review: This article was commissioned by the Guest Editor (Alan D. L. Sihoe) for the series "Thoracic
Surgery Worldwide" published in Fournal of Thoracic Disease. The article has undergone external peer review.

Peer Review File: Available at https://jtd.amegroups.com/ article/view/10.21037/jtd-21-1302/prf

Conflicts of Interest: Both authors have completed the ICMJE uniform disclosure form (available at https://jtd.amegroups. com/article/view/10.21037/jtd-21-1302/coif). The series "Thoracic Surgery Worldwide" was commissioned by the editorial office without any funding or sponsorship. The authors have no other conflicts of interest to declare.

Ethical Statement: Both authors are accountable for all aspects of the work in ensuring that questions related to the accuracy or integrity of any part of the work are appropriately investigated and resolved.

Open Access Statement: This is an Open Access article distributed in accordance with the Creative Commons Attribution-NonCommercial-NoDerivs 4.0 International License (CC BY-NC-ND 4.0), which permits the noncommercial replication and distribution of the article with the strict proviso that no changes or edits are made and the original work is properly cited (including links to both the formal publication through the relevant DOI and the license). See: https://creativecommons.org/licenses/by-nc-nd/4.0/.

\section{References}

1. Wu TY, Majeed A, Kuo KN. An overview of the healthcare system in Taiwan. London J Prim Care (Abingdon) 2010;3:115-9.

2. Chen TH. An Analysis on the Disparity of Medical Utilization between Urban and Rural Districts in Taiwan. Taipei: National Taipei University of Nursing and Health Sciences; 2018.

3. Bureau of National Health Insurance, Department of Health, Executive Yuan, Taiwan. Universal Health Coverage in Taiwan. 2012. [Cited 10 Sep 2021]. Available online: http://www.nhi.gov.tw/Resource/webdata/21717_1 _20120808UniversalHealth Coverage.pdf

4. National Health Insurance Administration, Ministry of Health and Welfare, Taiwan, R.O.C. National Health Insurance Annual Report 2014-2015. [Cited 10 Sep 2021.] Available online: https://www.nhi.gov.tw/English/ Content_List.aspx?n=D8ECF7F6C9D80FC1\&topn=BCB 2B0D2433F6491 
5. Axfors C, Schmitt AM, Janiaud P, et al. Mortality outcomes with hydroxychloroquine and chloroquine in COVID-19 from an international collaborative meta-analysis of randomized trials. Nat Commun 2021;12:2349.

6. Hsu JC, Wei CF, Yang SC, et al. Lung cancer survival and mortality in Taiwan following the initial launch of targeted therapies: an interrupted time series study. BMJ Open 2020;10:e033427.

7. National Lung Screening Trial Research Team; Aberle DR, Adams AM, et al. Reduced lung-cancer mortality with low-dose computed tomographic screening. $\mathrm{N}$ Engl J Med 2011;365:395-409.

8. Yang P. PS01.02 National Lung Cancer Screening Program in Taiwan: The TALENT Study. J Thorac Oncol 2021;16:S58.

9. de Koning HJ, van der Aalst CM, de Jong PA, et al. Reduced Lung-Cancer Mortality with Volume CT Screening in a Randomized Trial. N Engl J Med 2020;382:503-13.

10. Arnold M, Ferlay J, van Berge Henegouwen MI, et al. Global burden of oesophageal and gastric cancer by histology and subsite in 2018. Gut 2020;69:1564-71.

11. Wu M, Zhao JK, Zhang ZF, et al. Smoking and alcohol drinking increased the risk of esophageal cancer among Chinese men but not women in a high-risk population. Cancer Causes Control 2011;22:649-57.

12. Keszei AP, Schouten LJ, Goldbohm RA, et al. Red and processed meat consumption and the risk of esophageal and gastric cancer subtypes in The Netherlands Cohort Study. Ann Oncol 2012;23:2319-26.

13. Islami F, Ren JS, Taylor PR, et al. Pickled vegetables and the risk of oesophageal cancer: a meta-analysis. Br J Cancer 2009;101:1641-7.

14. Islami F, Boffetta P, Ren JS, et al. High-temperature beverages and foods and esophageal cancer risk--a systematic review. Int J Cancer 2009;125:491-524.

15. Wu M, Liu AM, Kampman E, et al. Green tea drinking, high tea temperature and esophageal cancer in high- and low-risk areas of Jiangsu Province, China: a populationbased case-control study. Int J Cancer 2009;124:1907-13.

16. Cheng YF, Chen HS, Wu SC, et al. Esophageal squamous cell carcinoma and prognosis in Taiwan. Cancer Med 2018;7:4193-201.

17. Wang BY, Hung WH, Wu SC, et al. Comparison Between Esophagectomy and Definitive Chemoradiotherapy in Patients With Esophageal Cancer. Ann Thorac Surg 2019;107:1060-7.

18. Chao YK, Wen YW. Cost-effectiveness analysis of thoracoscopic versus open esophagectomy for esophageal cancer: a population-based study. Dis Esophagus 2021;34:doaa116.

19. Chen JS, Chan WK, Tsai KT, et al. Simple aspiration and drainage and intrapleural minocycline pleurodesis versus simple aspiration and drainage for the initial treatment of primary spontaneous pneumothorax: an open-label, parallel-group, prospective, randomised, controlled trial. Lancet 2013;381:1277-82.

20. Hsu HH, Liu YH, Chen HY, et al. Vicryl Mesh Coverage Reduced Recurrence After Bullectomy for Primary Spontaneous Pneumothorax. Ann Thorac Surg 2021;112:1609-15.

21. Liu HP, Lin PJ, Chang JP, et al. Video-assisted thoracic surgery. Manipulation without trocar in 112 consecutive procedures. Chest 1993;104:1452-4.

22. Liu HP, Chang CH, Lin PJ, et al. Video-assisted thoracic surgery. The Chang Gung experience. J Thorac Cardiovasc Surg 1994;108:834-40.

23. Wang BY, Huang JY, Ko JL, et al. A Population-Based Cost Analysis of Thoracoscopic Versus Open Lobectomy in Primary Lung Cancer. Ann Surg Oncol 2016;23:2094-8.

24. Rocco G, Martin-Ucar A, Passera E. Uniportal VATS wedge pulmonary resections. Ann Thorac Surg 2004;77:726-8.

25. Wang BY, Liu CY, Hsu PK, et al. Single-incision versus multiple-incision thoracoscopic lobectomy and segmentectomy: a propensity-matched analysis. Ann Surg 2015;261:793-9.

26. Hsu PK, Lin WC, Chang YC, et al. Multiinstitutional analysis of single-port video-assisted thoracoscopic anatomical resection for primary lung cancer. Ann Thorac Surg 2015;99:1739-44.

27. Liu HP, Chang CH, Lin PJ, et al. Video-assisted endoscopic esophagectomy with stapled intrathoracic esophagogastric anastomosis. World J Surg 1995;19:745-7.

28. Lee JM, Yang SM, Yang PW, et al. Single-incision laparothoracoscopic minimally invasive oesophagectomy to treat oesophageal cancert. Eur J Cardiothorac Surg 2016;49 Suppl 1:i59-63.

29. Lee JM, Chen SC, Yang SM, et al. Comparison of singleand multi-incision minimally invasive esophagectomy (MIE) for treating esophageal cancer: a propensitymatched study. Surg Endosc 2017;31:2925-31.

30. Wu CF, Gonzalez-Rivas D, Wen CT, et al. Comparative Short-Term Clinical Outcomes of Mediastinum Tumor Excision Performed by Conventional VATS and SinglePort VATS: Is It Worthwhile? Medicine (Baltimore) 2015;94:e1975.

31. Rogers ML, Duffy JP. Surgical aspects of chronic post- 
thoracotomy pain. Eur J Cardiothorac Surg 2000;18:711-6.

32. Hsu CP. Subxiphoid approach for thoracoscopic thymectomy. Surg Endosc 2002;16:1105.

33. Hsu CP, Chuang CY, Hsu NY, et al. Subxiphoid approach for video-assisted thoracoscopic extended thymectomy in treating myasthenia gravis. Interact Cardiovasc Thorac Surg 2002;1:4-8.

34. Liu CC, Wang BY, Shih CS, et al. Subxiphoid singleincision thoracoscopic left upper lobectomy. J Thorac Cardiovasc Surg 2014;148:3250-1.

35. Fan YJ, Lo PC, Hsu YY, et al. A retrospective study on the impact of bar flipping on the recurrence of pectus excavatum after the Nuss procedure. J Cardiothorac Surg 2021;16:244.

36. Nakashima S, Watanabe A, Obama T, et al. Need for preoperative computed tomography-guided localization in video-assisted thoracoscopic surgery pulmonary resections of metastatic pulmonary nodules. Ann Thorac Surg 2010;89:212-8.

37. Gill RR, Zheng Y, Barlow JS, et al. Image-guided video assisted thoracoscopic surgery (iVATS) - phase I-II clinical trial. J Surg Oncol 2015;112:18-25.

38. Hsieh MJ, Fang HY, Lin CC, et al. Single-stage localization and removal of small lung nodules through image-guided video-assisted thoracoscopic surgery. Eur J Cardiothorac Surg 2018;53:353-8.

39. Hsieh MJ, Wen CT, Fang HY, et al. Learning curve of image-guided video-assisted thoracoscopic surgery for small pulmonary nodules: A prospective analysis of 30 initial patients. J Thorac Cardiovasc Surg 2018;155:1825-1832.e1.

40. Chao YK, Pan KT, Wen CT, et al. A comparison of efficacy and safety of preoperative versus intraoperative computed tomography-guided thoracoscopic lung resection. J Thorac Cardiovasc Surg 2018;156:1974-1983.e1.

41. Chao YK, Pan KT, Wen CT, et al. Preoperative CT versus intraoperative hybrid DynaCT imaging for localization of small pulmonary nodules: a randomized controlled trial. Trials 2019;20:400.

42. Pompeo E, Tacconi F, Mineo D, et al. The role of awake video-assisted thoracoscopic surgery in spontaneous pneumothorax. J Thorac Cardiovasc Surg 2007;133:786-90.

43. Chen JS, Cheng YJ, Hung MH, et al. Nonintubated thoracoscopic lobectomy for lung cancer. Ann Surg 2011;254:1038-43.

Cite this article as: Gao X, Chao YK. Thoracic surgery in Taiwan. J Thorac Dis 2022;14(7):2712-2720. doi: 10.21037/jtd-211302
44. Chen KC, Cheng YJ, Hung MH, et al. Nonintubated thoracoscopic lung resection: a 3-year experience with 285 cases in a single institution. J Thorac Dis 2012;4:347-51.

45. Wu CY, Chen JS, Lin YS, et al. Feasibility and safety of nonintubated thoracoscopic lobectomy for geriatric lung cancer patients. Ann Thorac Surg 2013;95:405-11.

46. Liao HC, Yang SM, Hung MH, et al. Thoracoscopic Surgery Without Drainage Tube Placement for Peripheral Lung Nodules. Ann Thorac Surg 2020;109:887-93.

47. Chao YK, Hsieh MJ, Liu YH, et al. Lymph Node Evaluation in Robot-Assisted Versus Video-Assisted Thoracoscopic Esophagectomy for Esophageal Squamous Cell Carcinoma: A Propensity-Matched Analysis. World J Surg 2018;42:590-8.

48. Chao YK, Tsai CY, Illias AM, et al. A standardized procedure for upper mediastinal lymph node dissection improves the safety and efficacy of robotic McKeown oesophagectomy. Int J Med Robot 2021;17:e2244.

49. Chao YK, Li ZG, Wen YW, et al. Robotic-assisted Esophagectomy vs Video-Assisted Thoracoscopic Esophagectomy (REVATE): study protocol for a randomized controlled trial. Trials 2019;20:346.

50. Leow OQY, Cheng C, Chao YK. Trans-subxiphoid robotic surgery for anterior mediastinal disease: an initial case series. J Thorac Dis 2020;12:82-8.

51. Chang TN, Chen LW, Lee CP, et al. Microsurgical robotic suturing of sural nerve graft for sympathetic nerve reconstruction: a technical feasibility study. J Thorac Dis 2020;12:97-104.

52. Chu D, Chen RC, Lee CH, et al. Incidence and frequency of endoscopic sympathectomy for the treatment of hyperhidrosis palmaris in Taiwan. Kaohsiung J Med Sci 2010;26:123-9.

53. Chen LW, Goh M, Goh R, et al. Robotic-Assisted Peripheral Nerve Surgery: A Systematic Review. J Reconstr Microsurg 2021;37:503-13.

54. Taiwan Organ Registry and Sharing. Real-time statistics July 29, 2021 [Cited at 15 September 2021] Available online: https://www.torsc.org.tw/docDetail. jsp?uid=158\&pid=9\&doc_id=1176

55. Yang SM, Huang SC, Kuo SW, et al. Twenty-years of lung transplantation in Taiwan: Effects of cumulative institutional experience on early outcomes. J Formos Med Assoc 2017;116:862-8. 